\title{
2D and 3D imaging of the deformation behavior of partially devulcanized rubber/polypropylene blends
}

\author{
P. S. Garcia' ${ }^{1}$ R. F. Gouveia ${ }^{2}$, J. M. Maia ${ }^{3}$, C. H. Scuracchio ${ }^{4}$, S. A. Cruz $5^{5^{*}}$ \\ ${ }^{1}$ Department of Metallurgical and Materials Engineering, Universidade de São Paulo, São Paulo, Brazil \\ ${ }^{2}$ Brazilian Nanotechnology National Laboratory (LNNano), Brazilian Center for Research in Energy and Materials \\ (CNPEM), Campinas-SP, Brazil \\ ${ }^{3}$ Department of Macromolecular Science and Engineering, Case Western Reserve University, OH 44106-7202 Cleveland, \\ USA \\ ${ }^{4}$ Department of Materials Engineering, Universidade Federal de São Carlos, São Paulo, Brazil \\ ${ }^{5}$ Department of Chemistry, Universidade Federal de São Carlos, São Paulo, Brazil
}

Received 10 April 2018; accepted in revised form 21 June 2018

\begin{abstract}
The full understanding of the mechanisms involved in the development of polymer blend microstructure during its processing has not yet been achieved; the understanding of blends composed by a highly elastic dispersed phase is even more indefinite. The proposal of this work is to analyze the deformation behavior of a new system composed by a partially devulcanized rubber dispersed in polypropylene using 2D and 3D images, both as complementary tools. For this purpose, ground tire rubber (GTR) was partially devulcanized by microwave irradiation for different exposure periods. After this step, each treated rubber was incorporated into recycled PP. The molded blends were analyzed using effective tools as $2 \mathrm{D}$ and 3D images and rheological data. In general, the polymer blends exhibited refined microstructure, especially the blend composed of the most devulcanized rubber, even though they had high values of viscosity ratio $(\geq 4)$. Based on the 3D images, it is clear that breakup mechanisms of the dispersed phase, like parallel breakup, have played an important role in the evolution of the blend's microstructure, mainly in the region of higher shear rate during processing. However, in areas where the rubber is still vulcanized, the breakup may have been caused by erosion of its surface.
\end{abstract}

Keywords: recycling, polymer blends, rubber, devulcanization, microstructure

\section{Introduction}

Polypropylene (PP), which is one of the most consumed thermoplastic, presents limitations in some applications, such as those which requires impact strength at low operating temperatures [1]. These limitations become critical when the PP is submitted to the recycling process. In this case, it may undergo severe thermo-mechanical degradation, altering some intrinsic properties as the molar mass [2-4]. In this context, the insertion of elastomers, such as scrap tire rubber, as dispersed phase in a thermoplastic, could be a viable alternative for solving two serious problems: minimizing the disposal of post-consumer elastomeric products in landfills and dumps and increase the recycled PP properties, especially fracture toughness [1,5-10].

However, the improvement of the properties of the polymeric mixture can only be achieved if its microstructure is well controlled [5, 6]. In systems with vulcanized rubber as dispersed phase, a refined morphology is very difficult to obtain because of its threedimensional network, that make vulcanized rubber insoluble and infusible and unable to flow under the action of a flow field [10-14]. In this context, the 
use of devulcanized rubber in a thermoplastic can be feasible, since it presents low gel content (or low crosslink density), and it is able to flow under mechanical stress and at high temperatures [15-18]. Sripornsawat et al. [19] has reported that, in systems containing devulcanized rubber and copolyesters, it was observed that dynamically cured blends with devulcanized rubber exhibited smaller rubber domains than mixtures using vulcanized rubber. This was due to the higher interfacial area and interactions between the phases. Regarding toughness mechanism, Scuracchio et al. concluded that in mixtures of ultrasound devulcanized SBR dispersed in polystyrene (PS - as matrix phase), the toughening of PS can be achieved in two situations: (1) when the rubber has lower gel content; (2) when smaller particles of rubber are obtained. The processing parameters were fundamental factors to the morphological refinement of the blend. In this case, the particle size distribution of the devulcanized SBR was narrowed with the increasing of the shear rate [20].

Many other parameters are also undoubtedly important to obtain a refined morphology, as the viscosity ratio, the interfacial tension, blend composition and melt elasticity. The relevance of the study of the dispersed phase deformation behavior under flow is crucial to understand how these parameters can influence the disperse phase breakup in polymer-polymer systems [21-25]. Moreover, non-Newtonian blends with high viscosity ratio values are not yet well understood. Some authors have reported that, in these cases, the critical breakup conditions are not the same applied for Newtonian systems for many reasons [25-27]. In regular mixture systems, a polymer blend is subjected to complex stress fields during shear and extensional melt-flow and its morphological evolution will be ruled as a function of these complex factors. Also, the dispersed phase domains will be broken up, since the stress applied during the processing will overcome the interfacial forces. The characteristics of each phase of the blend are important factors to be taken into account as well. Some papers have described that, in systems with viscosity ratio above 2 up to 60 , distinct mechanisms can occur, as the erosion and the parallel breakup [26-28]. These mechanisms will be explained in this paper.

In this work, the proposal is to understand the deformation behavior of a new polymer blend system composed by rubber partially devulcanized by microwave, as the dispersed phase, in a recycled PP after the melt-mixing, using effective tools such as 2D and 3D images and rheological experiments. Each of these blends' dispersed phases (GTR) was exposed to microwave for different time periods, and the following aspects were analyzed: correlation among the devulcanization treatment, rheological behavior of each phase, and the final microstructure of each blend.

\section{Materials and methods}

\subsection{Materials}

The study was conducted using a commercial homopolymer polypropylene (Braskem HP502H) as the matrix. It was supplied by Braskem (Brazil) and has MFI of $2.2 \mathrm{~g} / 10 \mathrm{~min}\left(230^{\circ} \mathrm{C}, 2.16 \mathrm{~N}-\mathrm{ASTM} \mathrm{D}-1238\right)$, and density of $0.905 \mathrm{~g} / \mathrm{cm}^{3}$ (ASTM D-792).

The vulcanized ground tire rubber used in this work, originated from truck tire tread (supplied by Pirelli Company, Brazil), exhibited the most particle size (about 75\%) below 60 mesh (aperture size of $250 \mu \mathrm{m})$. The remaining particles composing a size range ranging from 100 mesh (aperture size of $150 \mu \mathrm{m}-7.6 \%$ ) to 80 mesh (aperture size of $180 \mu \mathrm{m}$ $-15.5 \%$ ). This rubber is majority composed of NR, SBR, carbon black (as filler) and processing oils, as previously determined [16]. In addition, it can contain other additives, as vulcanization additives and other fillers (in small amounts) in its composition.

\subsection{Methods}

\subsubsection{Recycling process}

Polypropylene samples

In order to obtain a better control over the final properties and purity of the thermoplastic, the recycling process was simulated using a virgin PP as the initial material. The recycling simulation consisted of two steps processing in co-rotating twin-screw extruder, model Imacom DRC, with $D=30 \mathrm{~mm}$ and $L / D=40$. The first and second processing was run at screw speeds of 150 and $200 \mathrm{rpm}$, respectively, using the following temperature profile: $110 / 125 / 195 / 245 / 250 /$ $250 / 250 / 240 / 240 / 245 / 250^{\circ} \mathrm{C}$. After processing, the MFI of recycled PP (PPr) was measured and had the value of $6.1 \mathrm{~g} / 10 \mathrm{~min}\left(230^{\circ} \mathrm{C}, 2.16 \mathrm{~N}\right.$-ASTM D-1238).

\section{Ground tire rubber (GTR)}

Vulcanized ground tire rubber (GTRv) samples were treated in a conventional microwave oven Brastemp ${ }^{\circledR}$ model BM535BBNH with $820 \mathrm{~W}$ and a stirring 
system to homogenize the samples. About $60 \mathrm{~g}$ of the GTRv were exposed to microwave in different exposure periods: during $3 \mathrm{~min}$ (GTR3); $5 \mathrm{~min}$ (GTR5); 6 min (GTR6); and 7 min (GTR7). After each exposition time to microwave, each sample was homogenized in a two-roll mill to enhance the uniformity of the devulcanized parts and those that are still remained vulcanized. Samples were cut in small pieces $(\sim 0.5 \times 0.5 \times 0.5 \mathrm{~cm})$ to enhance the mixing into PPr. All rubbers used in this paper are well described in a previous work [16].

\subsubsection{Preparation of the blends}

The first mixture was prepared using $\operatorname{PPr}$ (matrix phase $-85 \mathrm{wt} \%$ ) and vulcanized rubber (GTRv $15 \mathrm{wt} \%)$. On the same proportion, blends composed of PPr (matrix phase) and devulcanized GTR (at different microwave exposure periods) were prepared. These samples were identified according to the nomenclatures: PPr/GTR5; PPr/GTR6; and GTR7. All mixtures were prepared in a co-rotating twinscrew extruder Werner-Pfleiderer ZSK-30 with $L / D=30$, with intensive mixing profile. The screw speed used was of $150 \mathrm{rpm}$, and the temperature profile of $190 / 195 / 190 / 190 / 190 / 195^{\circ} \mathrm{C}$. After the extrusion process, these materials were injection molded in a ROMI Primax $65 \mathrm{R}$ at $200^{\circ} \mathrm{C}$ to obtain standard specimens of impact bars.

\subsection{Characterization}

In order to understand the deformation process and breakup mechanisms of the vulcanized and partially devulcanized rubber into recycled polypropylene, morphological and rheological analysis were carried out.

\subsubsection{Morphological measurements}

$2 D$ images using scanning electron microscopy (SEM)

The morphology of the blends was studied using scanning electron microscopy (SEM) Philips XL-30 FEG at an acceleration voltage of $5 \mathrm{kV}$. The injection molded specimens were immersed by three hours in liquid nitrogen and the transversal section was cryofractured. The rubbery phase was etched by a solution of $30 \mathrm{~mL}$ of $\mathrm{H}_{3} \mathrm{PO}_{4}, 30 \mathrm{~mL}$ of distilled water, $10 \mathrm{~mL}^{\circ} \mathrm{H}_{2} \mathrm{SO}_{4}$, and $5 \mathrm{~g}$ of $\mathrm{CrO}_{3}$ at $70^{\circ} \mathrm{C}$ for $8 \mathrm{~min}$. All the fracture surfaces were then coated by a thin layer of gold (sputtered by $0.5 \mathrm{~min}$ ). The average diameter of the dispersed particles and their size distribution were evaluated by means of an image analysis of micrographs of fractured surface using the software Image J and Adobe Photoshop. The average number $\left(D_{\mathrm{n}}\right)$ and the average volume $\left(D_{\mathrm{w}}\right)$ diameter were obtained using the Equations (1) and (2):

$$
\begin{aligned}
& D_{\mathrm{n}}=\frac{1}{N} \sum_{\mathrm{i}} n_{\mathrm{i}} D_{\mathrm{i}} \\
& D_{\mathrm{w}}=\frac{\sum_{\mathrm{i}} f\left(D_{\mathrm{i}}\right) V_{\mathrm{i}} D_{\mathrm{i}}}{\sum_{\mathrm{i}} f\left(D_{\mathrm{i}}\right) V_{\mathrm{i}}}=\frac{\sum_{\mathrm{i}} n_{\mathrm{i}} D_{\mathrm{i}}^{4}}{\sum_{\mathrm{i}} n_{\mathrm{i}} D_{\mathrm{i}}^{3}}
\end{aligned}
$$

where $D_{\mathrm{i}}$ represents the particle diameter of the dispersed phase, $N$ represents the number of the particle, $n_{\mathrm{i}}$ and $V_{\mathrm{i}}$ represent the number and volume of the particles with diameter $D_{\mathrm{i}}$, respectively [29]. About 500 particles were considered to calculate these parameters. The Saltikov's correction was used for these calculations. The $D_{\mathrm{n}} / D_{\mathrm{w}}$ values were also calculated and represents the dispersion of the particle sizes (Polydispersity Index, PDI).

\section{$3 D$ images using $X$-ray microtomography}

$\mathrm{X}$-ray microtomography images were acquired using a Skyscan (Bruker) - 1272 instrument operating with $\mathrm{X}$-ray source voltage at $20 \mathrm{kV}$ and current at $175 \mu \mathrm{A}$. The nominal resolution was $5 \mu \mathrm{m}$ using the X-ray detector of 1224X820 pixels. NRecon software (Software Version 1.6.9.8, Bruker MicroCT ${ }^{\circledR}$ ) was used to reconstruct cross-section images from microtomography projections to 3D images, using Feldkamp algorithm. The same electronic density contrast limits were selected for all samples, permitting comparisons. CTVox software (v. 2.2.3.0, SkyScan) was used for $3 \mathrm{D}$ visualization and image acquisition. The morphometric analyses were quantified using the $\mathrm{CT}$ analyzer software (Software Version 1.14.4.1, Bruker MicroCT $\left.{ }^{\circledR}\right)$. For the acquisition of all quantitative parameters the p-reset VOI (volume object of interest) was of $9 \mathrm{~mm}^{3}$.

\subsubsection{Rheological measurements}

The melt-viscosity of the raw materials (PPr and devulcanized rubbers) were measured using a highpressure capillary rheometer Ceast SR20 (Instron) with a capillary die of $1 \mathrm{~mm}$ and $L / D$ ratio of 20 . Measurements were performed at $190^{\circ} \mathrm{C}$ over a shear rate range between 300 and $15000 \mathrm{~s}^{-1}$. The data were corrected according to the Rabinowitsch correction for non-Newtonian behavior, whereas the Bagley 
correction was neglected due to the high $L / D$ ratio [30]. The influence of the melt-viscosity ratio between GTR and PPr was also studied in order to understand the morphology of blends.

Another rheological characterization of the samples was performed using a controlled stress rheometer (model Physica MCR 501 from Anton Paar) with a parallel plate geometry ( $25 \mathrm{~mm}$ diameter, gap of $1 \mathrm{~mm})$ at $190^{\circ} \mathrm{C}$ in a nitrogen atmosphere. All samples were prepared using disk-shaped samples, obtained by compression molding of impact bars at $190^{\circ} \mathrm{C}$ for $5 \mathrm{~min}$. Dynamic frequency sweep test were performed from 300 to $0.1 \mathrm{rad} / \mathrm{s}$ at $2.5 \%$ strain, which proved to be in the linear viscoelastic range, according to a previous strain sweep test.

\section{Results}

\subsection{Thermoplastic (continuous} phase)/partially devulcanized rubber (dispersed phase): Why is this mixture considered a polymer blend?

According to the literature $[5,6]$, polymer blends are composed by a physical mixture of at least two polymers, where both can flow under mechanical stress and at high temperatures. In a previous work [16], it was demonstrated that it is possible to make this treated rubber to be fluid if a certain percentage of its crosslinked structure is broken. Above $27.0 \%$ of crosslink breakup is sufficient to make this possible (Table 1). When submitted to long exposure periods to microwave ( $\geq 5 \mathrm{~min}$ ), the chemical structure of a vulcanized elastomer can be highly modified, by breaking mainly the C-S and S-S bonds, as also reported by de Sousa et al. [18]. At high shear rates, the higher structural change undergone by the rubber, the lower the viscosity value, leading to higher flow rate. On the other hand, the vulcanized elastomers or less devulcanized materials, such as the GTR3 sample, are not able to flow neither at high temperatures $\left(190^{\circ} \mathrm{C}\right)$ nor at high shear rates [16]. Thus, the mixtures of devulcanized tire rubber (with sol phase or soluble fraction $\geq 27.0 \%$ ) in recycled polypropylene were considered polymer blends; however, the mixture of this same thermoplastic with vulcanized tire rubber (or with less devulcanized rubber) was considered a filled polymer.

\subsection{Understanding the relationship between flow behavior of partially devulcanized rubber and its drop size in a thermoplastic matrix}

All immiscible polymer blends present a direct correlation among the microstructure, viscosity ratio, composition (percentage and/or chemical structure), interfacial tension of the phases and mixing conditions (melt temperature, shear stress) [5, 6, 31]. The comprehension of the deformation behavior of this rubber under flow will be based on these factors, as follows.

\subsubsection{Rheological and morphological aspects}

The literature reports that there is a direct relationship between the viscosity ratio (dispersed phase viscosity $\left[\eta_{\mathrm{d}}\right]$ / matrix viscosity $\left.\left[\eta_{\mathrm{m}}\right]\right)$ and the dispersed phase domain size $[5,6]$. One of the premises is that the lower the viscosity ratio (dispersed phase viscosity $<$ matrix viscosity) the higher the capacity of the polymeric matrix to transfer stress to dispersed phase, promoting the morphology refinement. The dispersed phase can be stretched into fibrils, and it can be eventually broken up into smaller droplets (or smaller particles) $[5,6]$. According to Grace, in a rotational shear field and in Newtonian system, the droplets are broken up more easily in viscosity ratio between 0.1 and 1 . Outside this range, it would be necessary to use much higher values of shear rate to obtain smaller droplets. When the viscosity ratio is above 3.5, the dispersed phase tends only to deform or retain its spherical shape, but it does not break up [24]. In this work, Figure $1 \mathrm{~b}$ shows that the rubbers viscosities are at least four times higher than the thermoplastic viscosity. The lowest viscosity ratio was obtained for

Table 1. Viscosity value of the devulcanized rubbers (in different periods) under different shear rates.

\begin{tabular}{|c|c|c|c|c|c|c|}
\hline \multirow[t]{2}{*}{ Samples } & \multirow{2}{*}{$\begin{array}{l}\text { Sol content } \\
{[\%]}\end{array}$} & \multicolumn{5}{|c|}{$\begin{array}{l}\text { Viscosity value in different shear rates } \\
{[\mathrm{Pa} \cdot \mathrm{s}]}\end{array}$} \\
\hline & & $450 s^{-1}$ & $1000 s^{-1}$ & $5000 \mathrm{~s}^{-1}$ & $10000 \mathrm{~s}^{-1}$ & $25000 \mathrm{~s}^{-1}$ \\
\hline GTR3 & 16.5 & Not flow & Not flow & Not flow & Not flow & Not flow \\
\hline GTR5 & 27.0 & 1675 & 1123 & 547 & 486 & 455 \\
\hline GTR6 & 28.7 & 1476 & 960 & 340 & 225 & 136 \\
\hline GTR7 & 31.0 & 959 & 721 & 286 & 195 & 147 \\
\hline
\end{tabular}



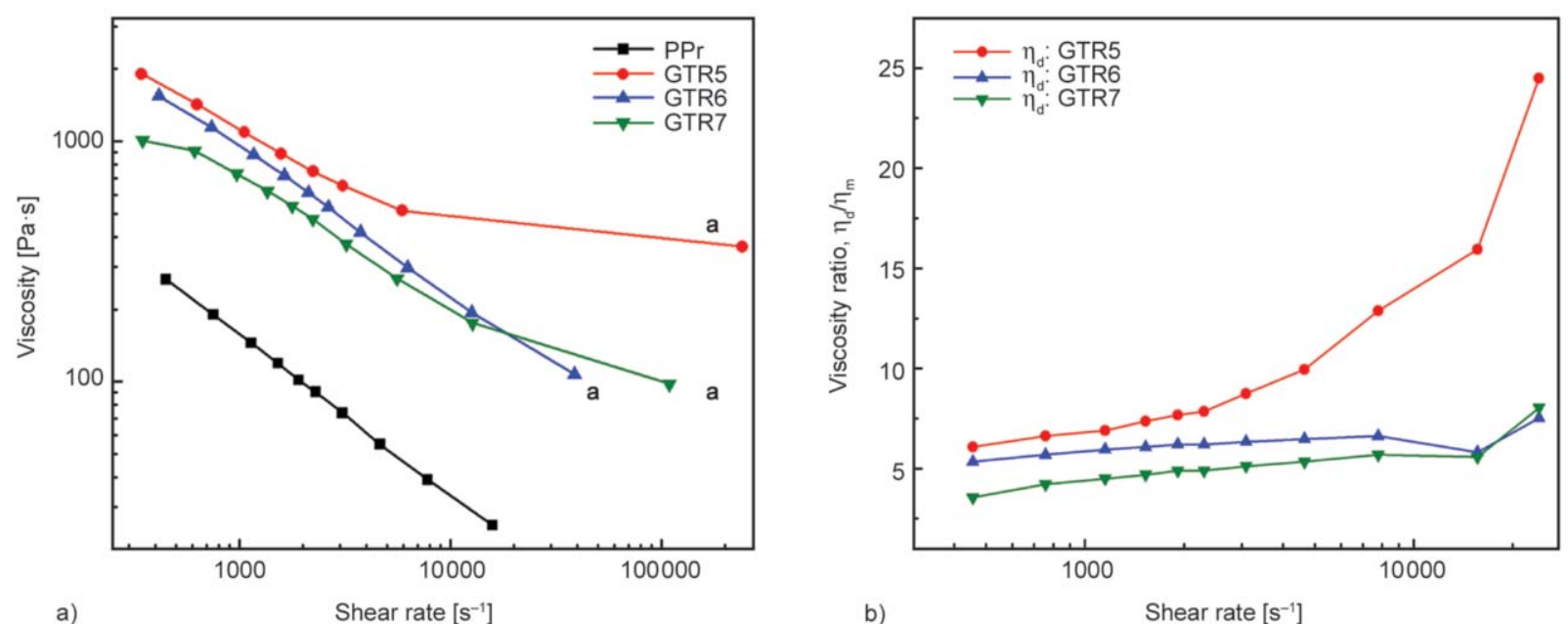

Figure 1. (a) Viscosity versus shear rate for PPr and devulcanized rubber samples (b) viscosity ratio values of devulcanized GTR (in different periods)/PPr. Ps: the curves represented by letter a (Figure 1a) have already been cited in the previous work [16].

the GTR7 sample, whereas the less devulcanized rubber (GTR5) exhibited the highest viscosity ratio, as already expected. It is worth mentioning that the viscosity ratio values (Figure 1b) were calculated from data of the Figure 1a. By correlating the viscosity ratio data with the final morphology of each polymer blend, it was expected to observe large particles sizes. When comparing the micrographs of the blends composed by dispersed rubbery phase with distinct devulcanization degrees, Figure 2 shows a significant difference in the dispersion of the rubber into PPr. The histograms (Figure 2) and Table 2 illustrate these results.

It is interesting to point out that the sample with the most devulcanized rubber (PPr/GTR7) exhibited the most refined morphology (lower values of average volume $\left(D_{\mathrm{w}}\right)$ and average number $\left(D_{\mathrm{n}}\right)$ diameter $)$, even though the GTR7 has $69.0 \%$ of crosslink density in its structure, as seen in Table 1. This sample also exhibited the most spherical particles. The PPr/ GTR5 sample, in which the dispersed phase presented the lowest devulcanization level, exhibited larger and more irregular particles with larger polydispersity (PDI) values. These results indicate that long exposure periods to microwave can interfere positively in the breaking of these particles during the processing. Comparing the rubbery domain size before being incorporated into $\operatorname{PPr}$ (rubber size: $0.5 \times 0.5 \times 0.5 \mathrm{~cm}$ ) and after (Figure 2), it can be concluded that the applied conditions on the processing were able to reduce the rubber size. Probably, the rubber suffered the influence of complex flow fields, with the simultaneous presence of shear and extensional flows. By comparing both the shear and extensional flows, the extensional is more effective than the shear flow to generating smaller particles (or droplets) in systems with high viscosity ratio [32].

When comparing the morphology of the blends (Figure 2 ) to the composite ( $\mathrm{PPr} / \mathrm{GTRv}$ - Figure 3), a notable difference is seen in their micrographs. It seems that the etching process applied to all samples could extract, or solubilize, only the sol phase (the actually devulcanized portion of the rubber). Figure 2 shows that for all blends, the droplet dispersion type morphologies were obtained, represented by dark holes. However, the micrograph of the PPr/GTRv sample did not exhibit the same pattern. The vulcanized portion could not be removed by the acid solution, as already reported in the literature [33]. Analyzing this latter result, the presence of a few portions of vulcanized material in all blends may be considered as well.

\subsubsection{Rheological behavior in the linear viscoelastic regime}

Figure 4 shows the effect of different dispersed rubbery phases (devulcanized at different periods and/or still vulcanized) on the viscosity of each blend in the linear viscoelastic regime.

It is well-known that data at the lower oscillation frequencies are sensitive to the size of the dispersed phase droplets. Since these rubbers have higher viscosities values than the one of the PPr, due to their high molar mass and crosslinks, it was already expected that there would be a slight increase in the viscosity values of the blends (or of the filled polymer). 
PPr/GTR5

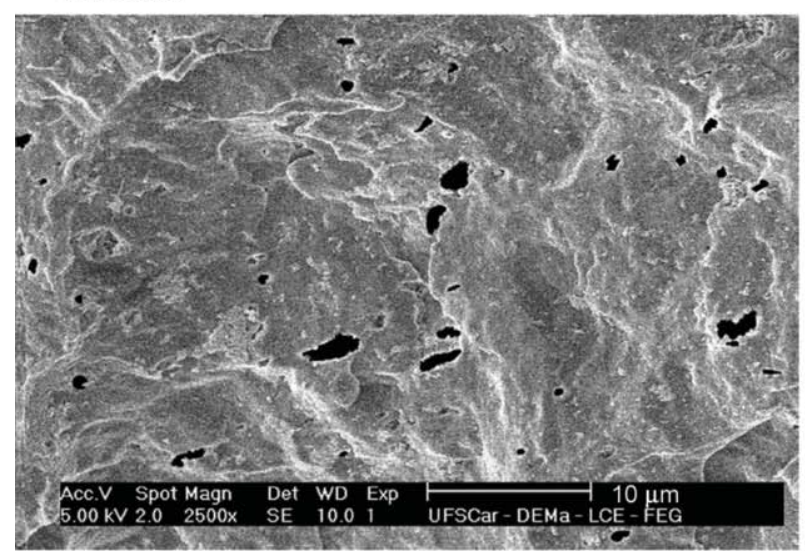

PPI/GTR6

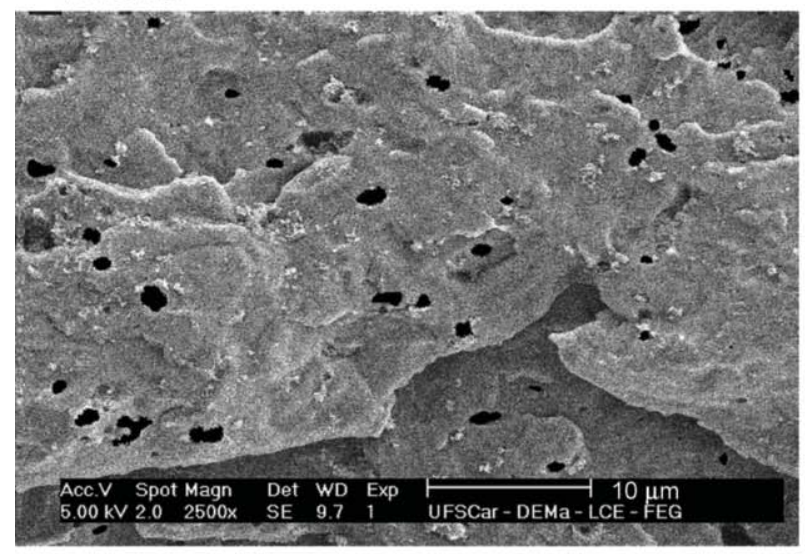

PPr/GTR7
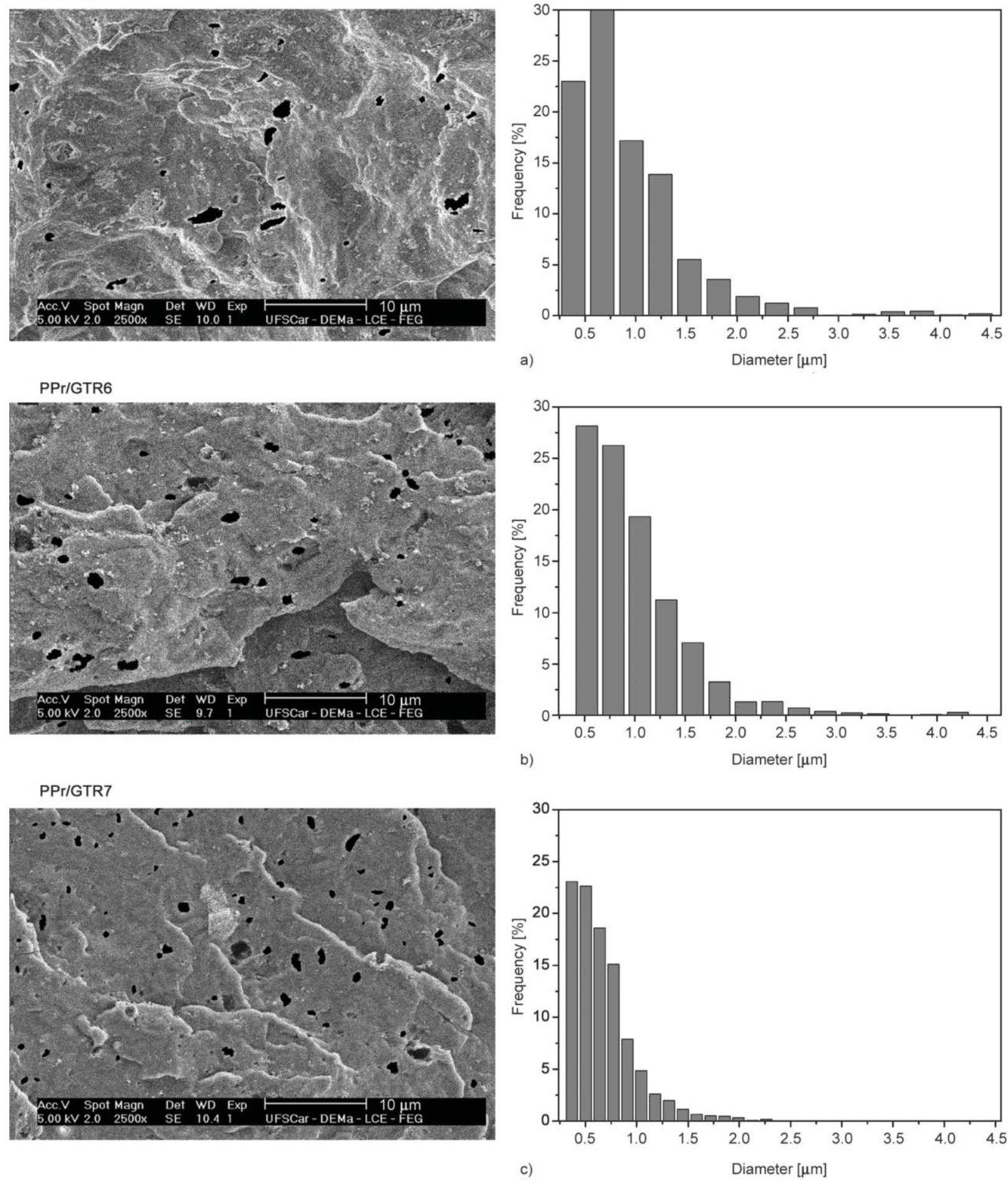

Figure 2. SEM micrographs (2D images) of surfaces of PPr/devulcanized GTR blends (85/15). Also, the histogram of each sample is presented in this figure.

Table 2. Quantification of the morphology for the different blends.

\begin{tabular}{|l|c|c|c|}
\hline \multicolumn{1}{|c|}{ Samples } & $\begin{array}{c}\boldsymbol{D}_{\mathbf{w}} \\
{[\boldsymbol{\mu \mathbf { m } ]}}\end{array}$ & $\begin{array}{c}\boldsymbol{D}_{\mathbf{n}} \\
{[\boldsymbol{\mu} \mathbf{m}]}\end{array}$ & $\begin{array}{c}\boldsymbol{D}_{\mathbf{w}} / \boldsymbol{D}_{\mathbf{n}} \\
{[\mathbf{P D I}]}\end{array}$ \\
\hline $\mathrm{PPr} / \mathrm{GTR} 5$ & 2.40 & 0.92 & 2.59 \\
\hline $\mathrm{PPr} / \mathrm{GTR} 6$ & 2.15 & 0.99 & 2.16 \\
\hline $\mathrm{PPr} / \mathrm{GTR} 7$ & 1.18 & 0.67 & 1.77 \\
\hline
\end{tabular}




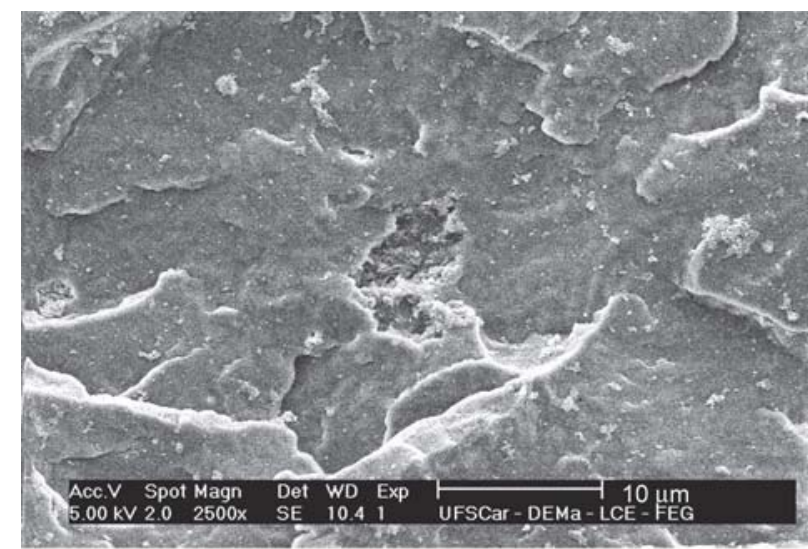

PPr/GTRv

Figure 3. SEM micrograph (2D images) of criofractured surface of PPr/vulcanized GTR composite (85/15).

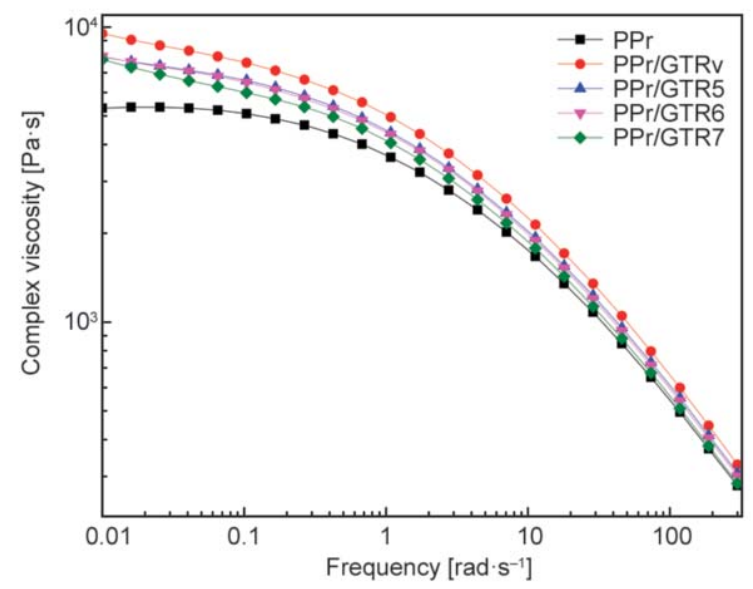

Figure 4. Complex viscosity of $\mathrm{PPr}, \mathrm{PPr} /$ devulcanized GTR blends $(85 / 15)$ and PPr/GTRv $(85 / 15)$ at $190^{\circ} \mathrm{C}$.

However, all the studied polymer blends had similar results among themselves. Although each of the rubbers was submitted to different time periods, in order to devulcanize them (which affected differently its particle size and its molecular structure), it was expected to note some difference at the interfacial interactions among the phases. However, this was not the case. Here, it is worth mentioning that the partially devulcanized rubber samples did not revulcanize upon heating during the processing, since the absence of revulcanization was observed during the rheological analysis, carried on in an oscillating disk rheometer (ODR) at $190^{\circ} \mathrm{C}$ for $5 \mathrm{~min}$, as described in the previous work [16].

Regarding storage modulus at low frequencies, as shown in Figure 5, interesting results were noticed. At low frequencies, PPr chains could relax and exhibited a typical terminal behavior $\left(G^{\prime} \sim \omega^{2}\right)$. With the presence of dispersed phase, this behavior was changed. In these cases, the typical terminal behavior

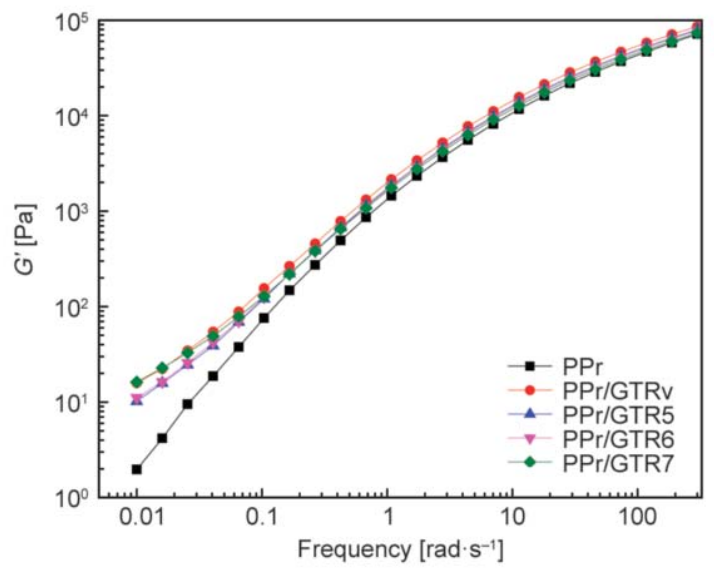

Figure 5. Storage modulus of $\mathrm{PPr}, \mathrm{PPr} /$ devulcanized GTR blends $(85 / 15)$ and PPr/GTRv composite $(85 / 15)$ at $190^{\circ} \mathrm{C}$.

disappeared and there was an increase of the elasticity, as expected [34]. For polymer blends, this behavior has already been reported in the literature [23]. The increase of elasticity at lower frequencies is attributed to a relaxation process of the dispersed particles (or droplets) when slightly deformed, recovering their original shape. In the case of polymeric composites, the non-existence of a typical terminal regime (with a tendency towards a pseudo-solid behavior) can be ascribed to the following mechanisms: (a) polymer-particle interactions: some polymeric chains are confined (immobilized) around particles either by frictional interactions or by chemical/physical interactions. Therefore, only a certain portion of polymeric chains can achieve the relaxation; (b) particle-particle interactions: above percolation threshold, particles can create a network structure, exhibiting a pseudo-solid behavior [35].

In the present work, it is believed that the partially devulcanized rubbers can act as non-inert fillers due to their high crosslink density. Probably, the non-inert particles (partially devulcanized rubber) interacted with the PPr chains (physically and/or chemically), where some chains got stuck, i.e. the PPr chains were anchored by these particles.

To explain the differences among the blends composed by devulcanized rubber, two points must be discussed: the devulcanized rubber's elasticity and the particles' size. As seen earlier, the most devulcanized rubber (GTR7) exhibited the lowest viscosity. Thus, with just this assumption, it might be concluded that the blend with GTR7 had the lowest $G^{\prime}$ value (due to lower elastic behavior of the GTR7). However, it should be reminded that the morphology 
is also a relevant factor. Among the blends, the most refined morphology sample was the PPr/GTR7 sample. It is known that the lower the particle size, the lower the rheological percolation threshold. In this case, the smallest rubbers possibly interacted with a higher matrix phase volume. Here, probably these two mechanisms are expected to counterbalance themselves.

\subsection{D morphology images: study of the dispersion and distribution of the vulcanized and partially devulcanized rubber after the injection molding process}

Regarding injection molding, it is known that the flow patterns are extremely complex and they will dictate the final morphology of the blends. In this context, three-dimensional images, obtained from the $\mathrm{X}$-ray microtomography, can be used to get a better

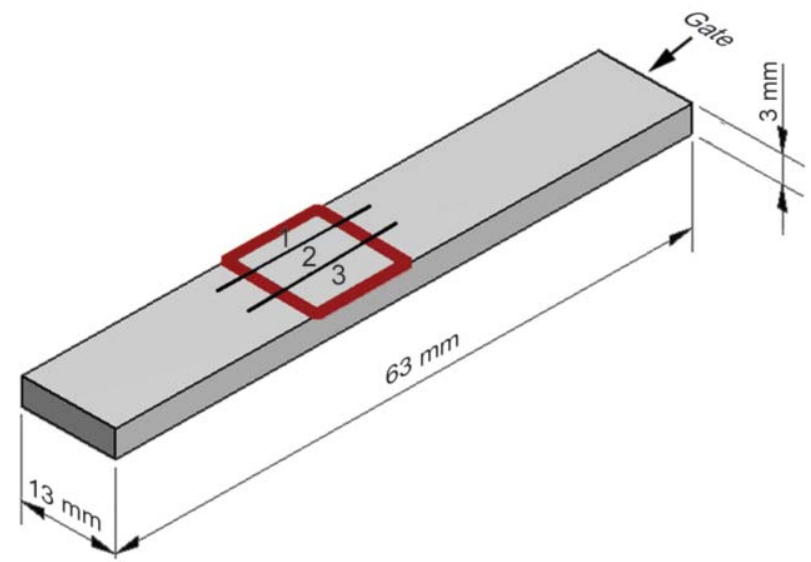

Figure 6. Illustration of injection molded sample (in 3D), highlighting the analyzed area (red square) by X-ray microtomography. overview of the real distribution and dispersion of the rubber particles in the samples when compared to the 2D images (obtained by SEM), even for the $\mathrm{PPr} / \mathrm{GTRv}$. Since it is a nondestructive technique, it is not necessary to extract any rubber using solvents to evaluate the morphology [36-39]. Thus, the analyses used the 3D images of injection molded samples. Only three areas (red square) of each sample were analyzed, as illustrated in Figure 6.

By analyzing the 3D microstructures of the Figures 7 and 8 , it was noticed that the blend PPr/GTR6 exhibited more refined morphology. Once again, it proves that the devulcanization process facilitated the breakup of the rubbers' particles during the mixture steps. Also, the PPr/GTR6 presented finer dispersion of the dispersed phase than the $\mathrm{PPr} / \mathrm{GTRv}$. Analyzing the same volume of each area (Section 1 or Section 3 (corner) and Section 2 (center)), it was also possible to confirm quantitatively the decreasing of the size of GTR6's particles in relation to the GTRv's, as seen in Figure 9. It is worth mentioning that the quantification of particle size smaller than $5.0 \mu \mathrm{m}$ was not possible due to the voxel size resolution limitations of this 3D technique.

Using the X-ray Microtomography's software, some other characteristics of the particles were also obtained. Table 3 shows the particles volume percentage and their degree of anisotropy in each sample (PPr/GTR6 and PPr/GTRv) in distinct sections (Figure 7 and 8 , respectively). In this manuscript, as previously shown, the percentage of rubber added into PPr was of $15 \mathrm{wt} \%$. However, the data (Table 3) showed that the measured percentage of GTR6 varied from 3.75 (Section 1 or 3) to 4.32 (Section 2), and
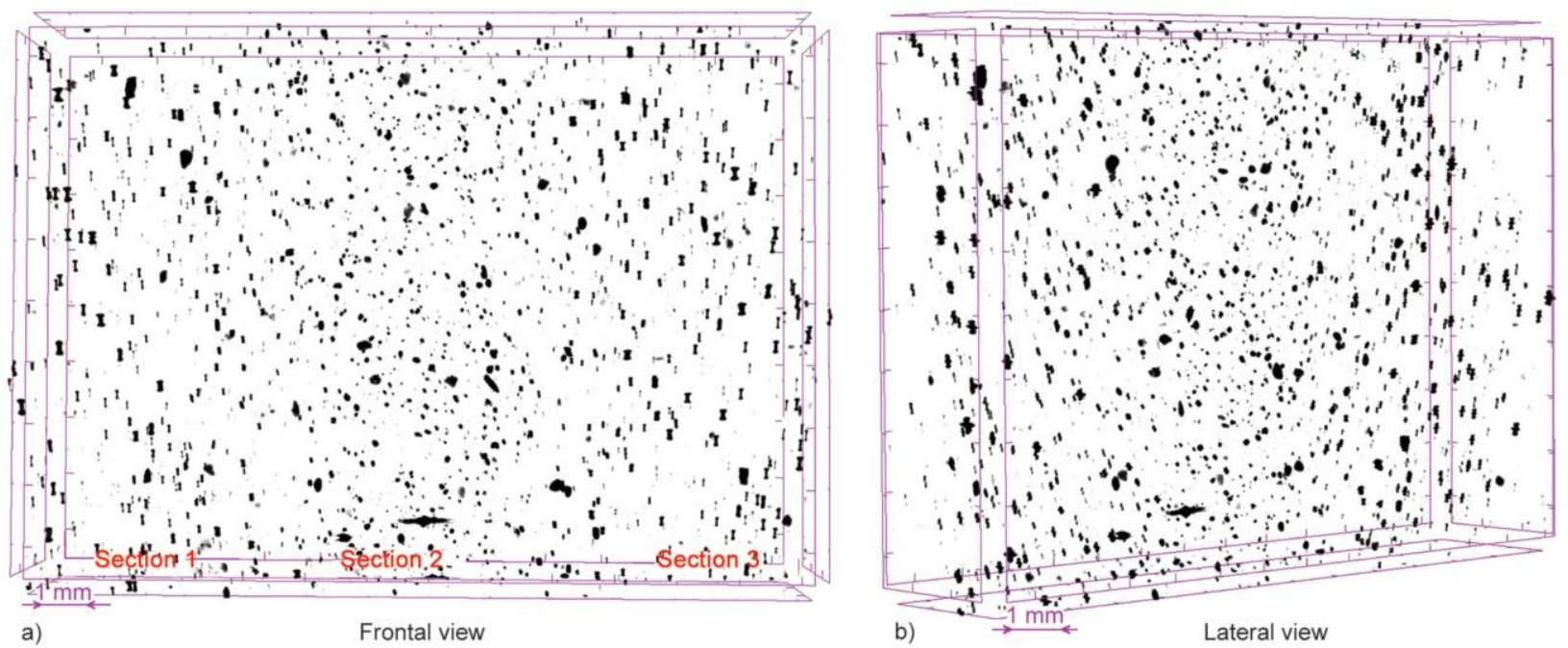

Figure 7. 3D images of the PPr/GTR6 (85/15) sample using X-ray microtomography. 

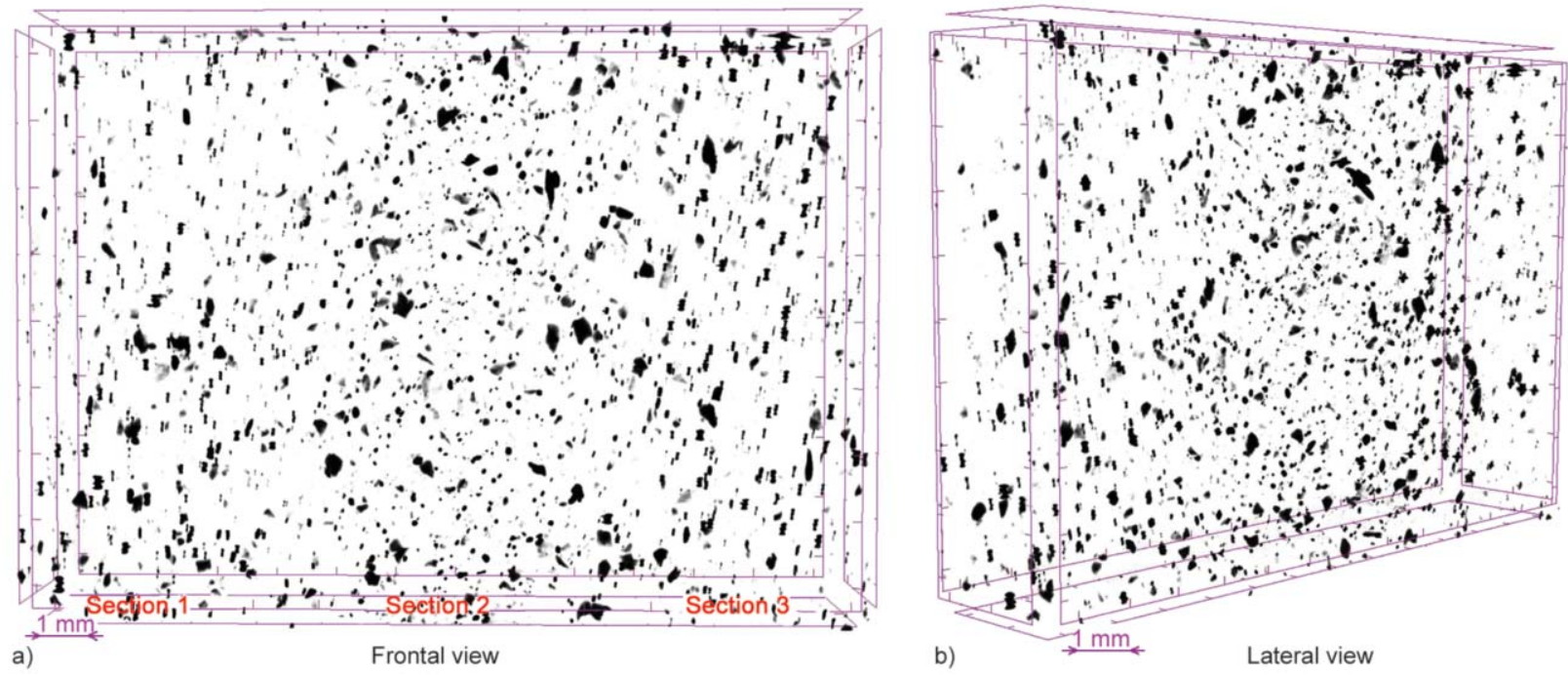

Figure 8. 3D images of the PPr/GTRv (85/15) sample using X-ray microtomography.

GTRv varied from 9.52 (Section 1 or 3 ) to 9.70 (Section 2). As this technique presents a limiting factor on the quantification of small particles, as seen early, it was concluded that the PPr/GTR6 sample has approximately $4 \%$ of GTR 6 with size above $5.0 \mu \mathrm{m}$ (mainly between 5 up to $40 \mu \mathrm{m}$ ) and $11 \%$ of particles below this value. Although there is a large amount of GTR6 particles with $D_{\mathrm{n}}$ of $0.99 \mu \mathrm{m}$ and $D_{\mathrm{w}}$ of $2.15 \mu \mathrm{m}$ (as shown in the 2D images - Figure 2), there is a reasonable quantity of particles with significantly large size (between 41 up to $320 \mu \mathrm{m}$ ). Regarding the PPr/GTRv sample, $10 \%$ of GTRv are above $5.0 \mu \mathrm{m}$, and there is a larger number of particles' size between 41-320 $\mu \mathrm{m}$ when compared to GTR6 particles' size. When comparing the 2D to the 3D images, it was observed that the technique to obtain 2D images presented limitations regarding the quantification of the particles as well. Using 2D images, it was not possible to observe large particles. Possibly the samples were cryofractured in areas

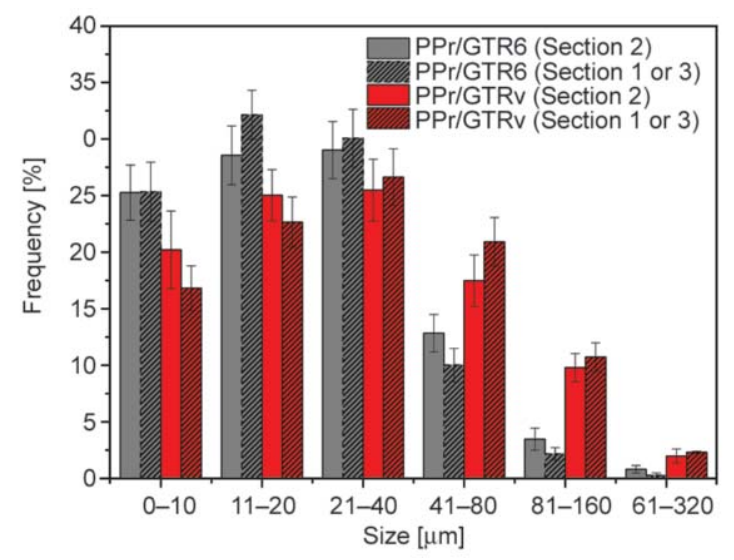

Figure 9. Rubber particle size histogram (the volume of interest present was $9 \mathrm{~mm}^{3}$ ).
Table 3. Percentage particles volume and their degree of anisotropy in each sample in distinct sections.

\begin{tabular}{|l|c|c|}
\hline \multicolumn{1}{|c|}{ Sample } & $\begin{array}{c}\text { Particle } \\
{[\%]}\end{array}$ & $\begin{array}{c}\text { Degree of } \\
\text { anisotropy }^{*}\end{array}$ \\
\hline PPr/GTR6 (Section 2 - center) & 4.32 & 1.30 \\
\hline PPr/GTR6 (Section 1 or 3 - corner) & 3.75 & 1.64 \\
\hline PPr/GTRv (Section 2 - center) & 9.70 & 1.79 \\
\hline PPr/GTRv (Section 1 or 3 - corner) & 9.52 & 1.91 \\
\hline
\end{tabular}

*Anisotropy is a measure of 3D symmetry with the presence of a preferential alignment of structures along a particular directional axis. The values were obtained by MicroCT software.

where there is not the presence of those particles. However, 2D images captured by MEV are more accurate to see small particles. Thus, we concluded the data has shown that both 2D and 3D images are complementary for understanding the microstructures of the polymer blends.

The evolution of the anisotropy of the dispersed phase with the increasing shear rate was observed in Figures 7, 8 and Table 3. It was noticed the slight stretching of the rubber (vulcanized and devulcanized samples) only in the section of higher shear rate (Section 1 and 3). In the middle of each sample (Section 2) the rubbers exhibited more circular shape. The results have shown that anisotropy increased from the central area to the lateral area, as follows: for PPr/GTR6: 1.64 (to theSection 1 or 3) and 1.30 (to the Section 2); for PPr/GTRv: 1.91 (to the Section 1 or 3) and 1.79 (to the Section 2).

According to literature [40-42], these anisotropic and isotropic structures, which are known as a phenomenon of skin-core morphology, come from the injection molding process. During the filling step of molding, the polymeric chains undergo orientational 
elongation resulting from fountain flow. When these chains touch the cold wall of the mold, they freeze immediately forming a skin highly oriented, where the shear will be maximum. Thus, in this region the dispersed phase will be highly elongated and this orientation will be maintained, whereas the central regions of the mold, the chains (or the dispersed phase) will have sufficient time to relax, reducing the anisotropy. The core morphology is represented by rubbers with a more rounded shape. It is worth mentioning that the shape of the rubber at higher shear rate sections will be discussed later.

\subsection{Particles shape and possible mechanisms of break of the dispersed rubbery phase}

The 2D images obtained by SEM (Figure 2) showed that, depending on the devulcanization degree undergone by the rubber, the dispersed phase can exhibit differences in its shape. At this point, the 3D images can provide better understanding of how the particles took shape during the process of injection molding.
Figures 7 and 8 show the devulcanized (GTR6) and vulcanized (GTRv) rubber, respectively, into PPr in the 3D scale. By correlating these images with Figures 10 and 11, interesting aspects were noticed.

The first point considers the more irregular shape of the rubbers, concerning both the vulcanized rubber (PPr/GTRv) and the least devulcanized rubber ( $\mathrm{PPr} /$ GTR5) into PPr. The micrographs (Figure 10b) illustrate that few particles in the region of higher shear rate appear stretched (see the red-highlighted). However, it is observed that one daughter particle (or daughter droplet) is almost peeling off its mother particle (or mother droplet), see Figure 10c. It is believed that this image can describe an erosion phenomenon.

An important work in literature has observed the same phenomenon at highly viscous systems. By studying polycarbonate (PC) drops in the polyethylene (PE) matrix under simple shear rate, where the viscosity ratio ranged of 6 up to 60, Lin and Sundararaj observed the erosion mechanism [28]. At low

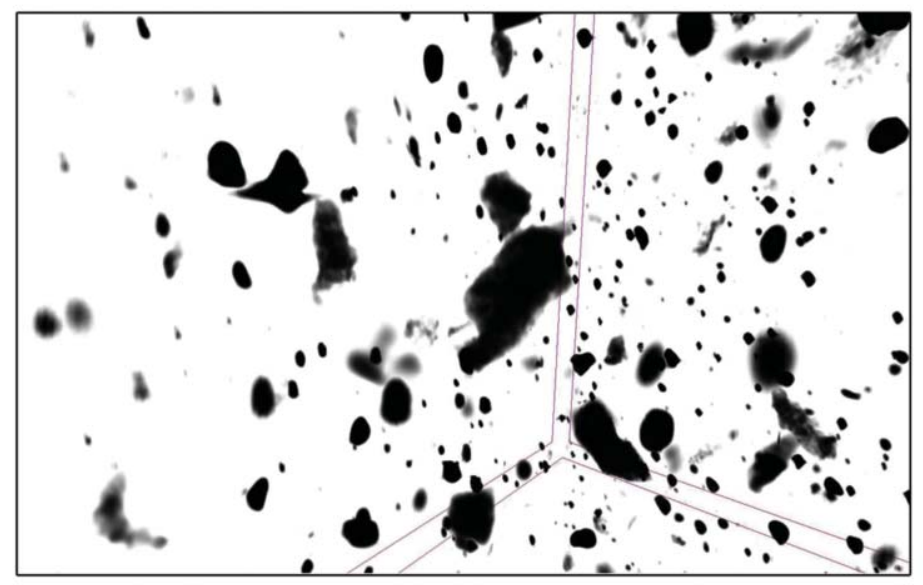

a)

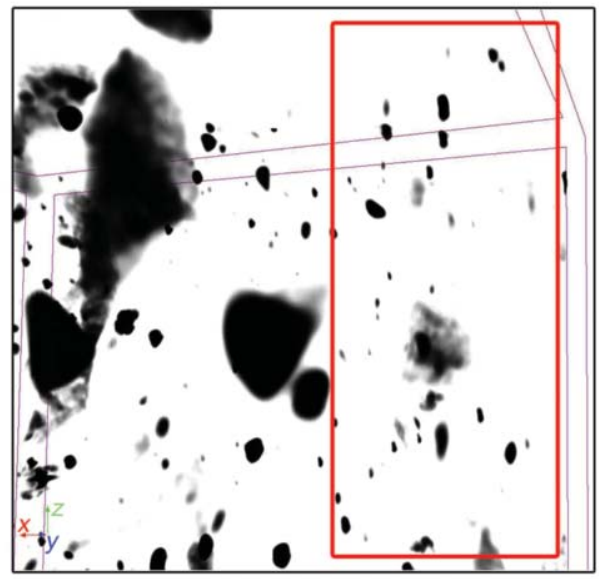

b)

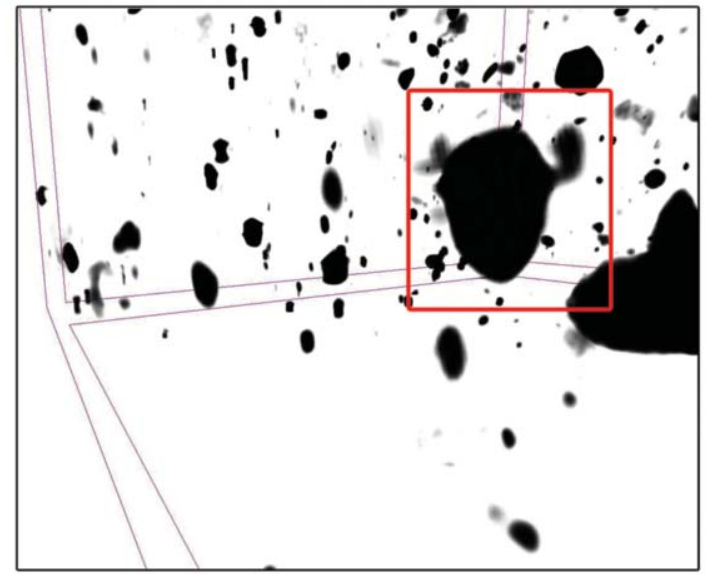

c)

Figure 10. 3D images of the PPr/GTRv sample in areas of higher shear rate. Letters a), b) and c) represent different analyzed areas. 


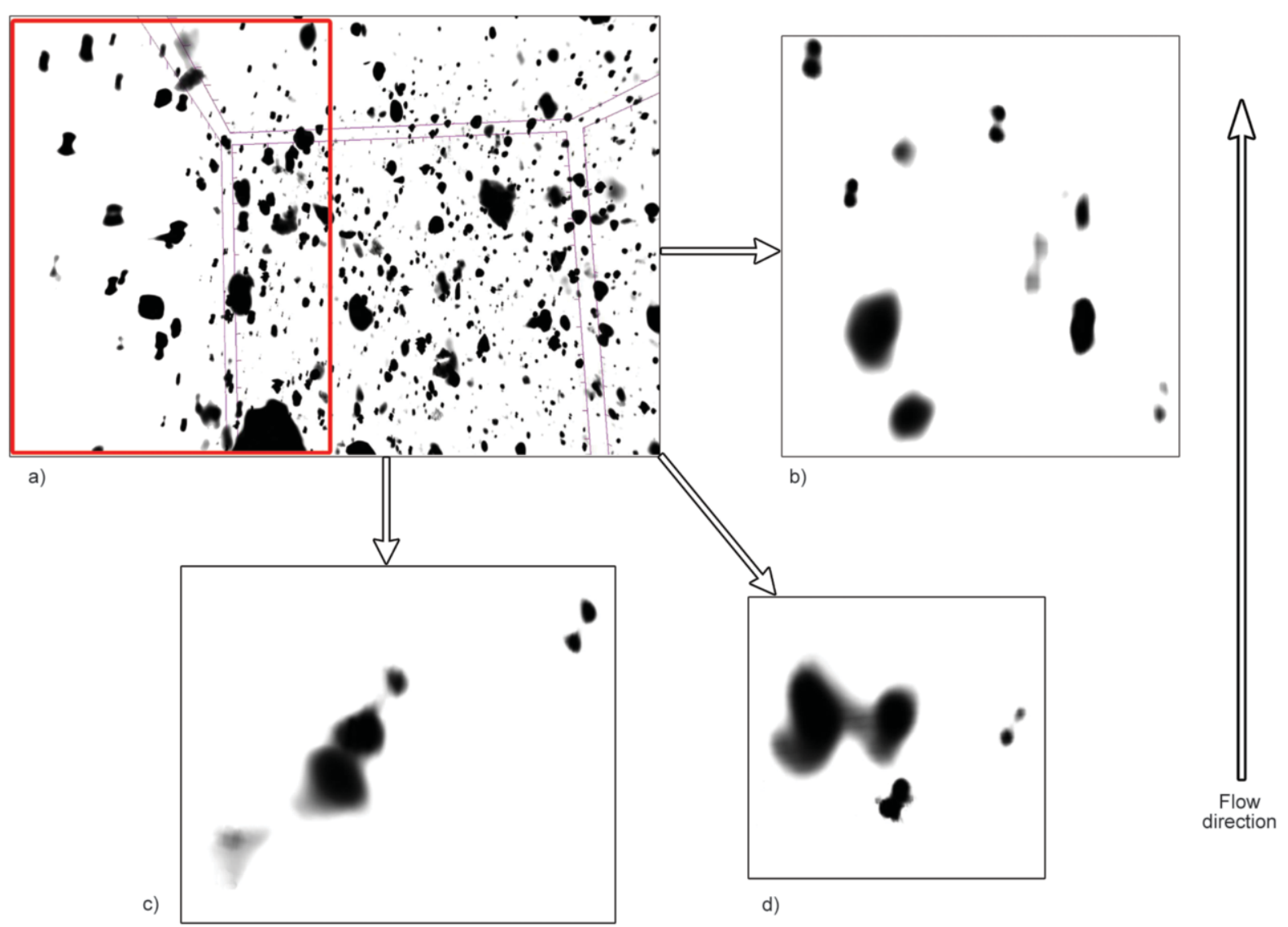

Figure 11. 3D images of the PPr/GTR6 sample in areas of higher shear rate, a) full image, b), c) and d) different areas highlighted.

shear rates, the authors noticed that the polycarbonate (PC) droplets were stretched under shear stress in the flow direction, and they also underwent deformation by the normal stress in the perpendicular direction to the flow. Under these circumstances, their shapes were changed, resulting in a diamond-like shape droplet. In this case, the numerical simulation showed that the maximum shear stress in the droplets surface could have reached values of one order of magnitude higher than inside the droplet itself and ten orders of magnitude higher than in the matrix phase. Thus, even in highly viscous systems, under high shear rate, small daughter droplets could be easily peeled off from their mother droplets,

Regarding the rubbery systems with high gel content, i.e., high crosslink density, a relevant point was raised by Scuracchio et al. [20]. The authors reported that in blends composed by devulcanizated SBR (by ultrasound) as dispersed phase into polystyrene (PS), the formation of fibril was not found. They attributed that to the fact the rubber was more elastic than viscous during the flow. Thus, the authors assumed that the breakup of these particles could have involved mechanisms such as the crack propagation.
So, in this work, we consider that both mechanisms can occur when the shear and elongational stresses are applied over a highly elastic rubber, i.e. with high crosslink density.

Figure 11 shows micrographs of the blend PPr/GTR6. Here it is also noticed stretched particles in the region of higher shear rate, where these ones are similar to the dumbbell-like shape particles. These stretched particles are apparently being broken up in the flow direction. Somehow, it seems that this kind of breakup is facilitated when the sol content is increased, and probably these particles will exhibit a finer microstructure with more spherical particles. Exceptionally, in the Figure $11 \mathrm{~d}$, it is seen there is a particle breakup in the parallel direction to the flow. Lin et al. [26] observed, under conditions where the viscosity ratio ranged from 2 up to 9 , using $\mathrm{PC}$ as dispersed phase and $\mathrm{PE}$ as matrix, a mechanism called by the authors as 'parallel breakup'. It means that, the droplets could break up after being elongated in the flow direction in the shape of a thin sheet. This sheet continues to be stretched along the flow, and the sheet breaks up in two smaller daughter droplets along the flow direction. For this to happen, it is necessary the droplets to 
behave more like a solid material. We believe that this same breakup mechanism (parallel breakup) has occurred regarding the partially devulcanized rubbers. Also, in both mixtures (PPr/GTRv and $\mathrm{PPr} /$ GTR6) there is probably a combination of all breakup mechanisms mentioned above. However, sometimes some mechanisms prevail over the other ones.

\section{Conclusions}

In order to better understand the deformation behavior of a highly elastic dispersed phase (partially devulcanized or vulcanized rubber $-15 \mathrm{wt} \%$ ) in a recycled polypropylene, the rheological aspects and the microstructures (using 2D and 3D analysis) of the mixtures were investigated. Based on 2D and 3D images and the rheological data, the following conclusions were drawn: (1) blend composed by the dispersed rubbery phase with the highest devulcanization level presented the most refined morphology. The devulcanization treatment contributed positively to the breakup of these particles during the processing, even in systems with viscosity ratio higher than four; (2) rheological results have showed that, under high shear rate, the partially devulcanized rubber (sol content $\geq 27 \%$ ) can flow. However, at low oscillation frequencies, it exhibits characteristics of a filler, due to its remaining high crosslink density; (3) by using the 3D images, the rubber breakup mechanism was better understood. Micrographs of mixtures with vulcanized rubber showed that, possibly the breakup of this rubber was caused by erosion of its surface. However, in systems with partially devulcanized rubber, it is noticed the higher occurrence of another kind of breakup mechanism, called parallel breakup; (4) It was concluded the SEM and X-ray microtomography techniques used to obtain the micrographs complement each other. The 3D images can show a better overview of the real distribution and the dispersion of the dispersed phase; however, this technique presents resolution limitations below $5 \mu \mathrm{m}$. Below that resolution, the SEM is the best technique to observe the morphology.

\section{Acknowledgements}

The authors are grateful to the Universidade Federal do ABC (UFABC) and Braskem S.A. for financial support and UFABC and Brazilian Nanotechnology National Laboratory (LNNano) for assistance in this project. We specially thank the Micro-CT staff for technical support (project number: Micro CT - 20883).

\section{References}

[1] Stehling F. C., Huff T., Speed C. S., Wissler G.: Structure and properties of rubber-modified polypropylene impact blends. Journal of Applied Polymer Science, 26, 2693-2711 (1981). https://doi.org/10.1002/app.1981.070260818

[2] da Costa H. M., Ramos V. D., de Oliveira M. G.: Degradation of polypropylene (PP) during multiple extrusions: Thermal analysis, mechanical properties and analysis of variance. Polymer Testing, 26, 676-684 (2007). https://doi.org/10.1016/j.polymertesting.2007.04.003

[3] Garcia P. S., Scuracchio C. H., Cruz S. A.: Effect of residual contaminants and of different types of extrusion processes on the rheological properties of the postconsumer polypropylene. Polymer Testing, 32, 12371243 (2013). https://doi.org/10.1016/j.polymertesting.2013.08.002

[4] Aurrekoetxea J., Sarrionandia M. A., Urrutibeascoa I., Maspoch M. Li.: Fracture behaviour of virgin and recycled isotactic polypropylene. Journal of Materials Science, 36, 5073-5078 (2001). https://oi.org/10.1023/A:1012460804698

[5] Utracki L. A.: Polymer blends handbook. Kluwer, London (2003).

[6] Harrats C., Thomas S., Groeninckx G.: Micro- and nanostructured multiphase polymer blend systems: Phase morphology and interfaces. CRC Press, Boca Raton (2006).

[7] Yokoyama Y., Ricco T.: Toughening of polypropylene by different elastomeric systems. Polymer, 39, 36753681 (1998).

https://doi.org/10.1016/S0032-3861(97)10358-5

[8] Zhang H., Wang J., Cao S., Shan A.: Toughened polypropylene with balanced rigidity (I): Preparation and chemical structure of toughening master batch. Polymers for Advanced Technologies, 11, 334-341 (2000). https://doi.org/10.1002/1099-1581(200007)11:7<334::AIDPAT976>3.0.CO;2-K

[9] Liang J. Z., Li R. K. Y.: Rubber toughening in polypropylene: A review. Journal of Applied Polymer Science, 77, 409-417 (2000).

https://doi.org/10.1002/(SICI)10974628(20000711)77:2\%3C409::AID-APP18\%3E3.0.CO;2-N

[10] Bandyopadhyay S., Agrawal S. L., Ameta R., Dasgupta S., Mukhopadhyay R., Saha Deuri A., Ameta S. C., Ameta R.: An overview of rubber recycling. Progress in Rubber Plastics Recycling Technology, 24, 73-112 (2008).

[11] Karger-Kocsis J., Mészáros L., Bárány T.: Ground tyre rubber (GTR) in thermoplastics, thermosets, and rubbers. Journal of Materials Science, 48, 1-38 (2013). https://doi.org/10.1007/s10853-012-6564-2

[12] Myhre M., Mackillop D. A.: Rubber recycling. Rubber Chemistry and Technology, 75, 429-474 (2002). https://doi.org/10.5254/1.3547678 
[13] Adhikari B., De D., Maiti S.: Reclamation and recycling of waste rubber. Progress in Polymer Science, 25, 909-948 (2000).

https://doi.org/10.1016/S0079-6700(00)00020-4

[14] Ramarad S., Khalid M., Ratnam C. T., Luqman Chuah A., Rashmi W.: Waste tire rubber in polymer blends: A review on the evolution, properties and future. Progress in Materials Science, 72, 100-140 (2015).

https://doi.org/10.1016/j.pmatsci.2015.02.004

[15] Scuracchio C. H., Waki D. A., da Silva M. L. C. P.: Thermal analysis of ground tire rubber devulcanized by microwaves. Journal of Thermal Analysis and Calorimetry, 87, 893-897 (2007).

https://doi.org/10.1007/s10973-005-7419-8

[16] Garcia P. S., de Sousa F. D. B., de Lima J. A., Cruz S. A., Scuracchio C. H.: Devulcanization of ground tire rubber: Physical and chemical changes after different microwave exposure times. Express Polymer Letters, 9, 1015-1026 (2015).

https://doi.org/10.3144/expresspolymlett.2015.91

[17] Tao G., He Q., Xia Y., Jia G., Yang H., Ma W.: The effect of devulcanization level on mechanical properties of reclaimed rubber by thermal-mechanical shearing devulcanization. Journal of Applied Polymer Science, 129, 2598-2605 (2013).

https://doi.org/10.1002/app.38976

[18] de Sousa F. D. B., Scuracchio C. H., Hu G-H., Hoppe S.: Devulcanization of waste tire rubber by microwaves. Polymer Degradation and Stability, 138, 169-181 (2017).

https://doi.org/10.1016/j.polymdegradstab.2017.03.008

[19] Sripornsawat B., Saiwari S., Pichaiyut S., Nakason C.: Influence of ground tire rubber devulcanization conditions on properties of its thermoplastic vulcanizate blends with copolyester. European Polymer Journal, 85, 279297 (2016).

https://doi.org/10.1016/j.eurpolymj.2016.10.031

[20] Scuracchio C. H., Bretas R. E. S., Isayev A. I.: Blends of PS with SBR devulcanized by ultrasound: Rheology and morphology. Journal of Elastomers and Plastics, 36, 45-75 (2004).

https://doi.org/10.1177/0095244304039913

[21] Taylor G. I.: The viscosity of a fluid containing small drops of another fluid. Proceedings of the Royal Society A: Mathematical, Physical and Engineering Sciences, 138, 41-48 (1932).

https://doi.org/10.1098/rspa.1932.0169

[22] Favis B. D., Chalifoux J. P.: The effect of viscosity ratio on the morphology of polypropylene/polycarbonate blends during processing. Polymer Engineering and Science, 27, 1591-1600 (1987). https://doi.org/10.1002/pen.760272105

[23] Mechbal N., Bousmina M.: Effect of copolymer addition on drop deformation during uniaxial elongation and during relaxation after cessation of flow. Macromolecules, 40, 967-975 (2007).

https://doi.org/10.1021/ma061292c
[24] Grace H. P.: Dispersion phenomena in high viscosity immiscible fluid systems and application of static mixers as dispersion devices in such systems. Chemical Engineering Communications, 14, 225-277 (1982). https://doi.org/10.1080/00986448208911047

[25] Wu S.: Formation of dispersed phase in incompatible polymer blends: Interfacial and rheological effects. Polymer Engineering and Science, 27, 335-343 (1987). https://doi.org/10.1002/pen.760270506

[26] Lin B., Mighri F., Huneault M. A., Sundararaj U.: Parallel breakup of polymer drops under simple shear. Macromolecular Rapid Communications, 24, 783-788 (2003).

https://doi.org/10.1002/marc.200350026

[27] Fortelný I., Jůza J., Dimzoski B.: Coalescence in quiescent polymer blends with a high content of the dispersed phase. European Polymer Journal, 48, 12301240 (2012).

https://doi.org/10.1016/j.eurpolymj.2012.04.017

[28] Lin B., Sundararaj U., Mighri F., Huneault M. A.: Erosion and breakup of polymer drops under simple shear in high viscosity ratio systems. Polymer Engineering and Science, 43, 891-904 (2003).

https://doi.org/10.1002/pen.10073

[29] Grizzuti N., Bifulco O.: Effects of coalescence and breakup on the steady-state morphology of an immiscible polymer blend in shear flow. Rheologica Acta, 36, 406-415 (1997).

https://doi.org/10.1007/BF00396327

[30] Han C. D.: Rheology and processing of polymeric materials, Volume 1: Polymer Rheology, Oxford University Press, New York (2007).

[31] Zuev V. V., Steinhoff B., Bronnikov S., Kothe H., Alig I.: Flow-induced size distribution and anisotropy of the minor phase droplets in a polypropylene/poly (ethylene-octene) copolymer blend: Interplay between breakup and coalescence. Polymer, 53, 755-760 (2012).

https://doi.org/10.1016/j.polymer.2011.12.046

[32] Testa C., Sigillo I., Grizzuti N.: Morphology evolution of immiscible polymer blends in complex flow fields. Polymer, 42, 5651-5659 (2001).

https://doi.org/10.1016/S0032-3861(01)00078-7

[33] Ezzati P., Ghasemi I., Karabi M., Azizi H.: Rheological behaviour of PP/EPDM blend: The effect of compatibilization. Iranian Polymer Journal, 17, 669-679 (2008).

[34] Mittal V.: Characterization techniques for polymer nanocomposites. Wiley, Weinheim (2012).

[35] Hassanabadi H. M., Rodrigue D.: Relationships between linear and nonlinear shear response of polymer nano-composites. Rheologica Acta, 51, 991-1005 (2012). https://doi.org/10.1007/s00397-012-0655-5

[36] Landis E. N., Keane D. T.: X-ray microtomography. Materials Characterization, 61, 1305-1316 (2010). https://doi.org/10.1016/j.matchar.2010.09.012 
[37] Nishikawa Y., Iizuka S., Takahashi M.: X-ray CT observation of a 'mosaic-tiling' structure and a 'wormlike' structure in the ternary polymer blends. Polymer, 54, 6267-6270 (2013).

https://doi.org/10.1016/j.polymer.2013.09.028

[38] Pyun A., Bell J. R., Won K. H., Weon B. M., Seol S. K., Je J. H., Macosko C. W.: Synchrotron X-ray microtomography for 3D imaging of polymer blends. Macromolecules, 40, 2029-2035 (2007).

https://doi.org/10.1021/ma062635+

[39] López-Barrón C. R., Macosko C. W.: Measurement of geometrical parameters in cocontinuous polymer blends: $3 \mathrm{D}$ versus $2 \mathrm{D}$ image analysis. Journal of Microscopy, 242, 242-249 (2011).

https://doi.org/10.1111/j.1365-2818.2010.03462.x
[40] Karger-Kocsis J., Csikai I.: Skin-core morphology and failure of injection-molded specimens of impact-modified polypropylene blends. Polymer Engineering and Science, 27, 241-253 (1987).

https://doi.org/10.1002/pen.760270403

[41] Fellahi S., Favis B. D., Fisa B.: Morphological stability in injection-moulded high-density polyethylene/polyamide-6 blends. Polymer, 37, 2615-2626 (1996). https://doi.org/10.1016/0032-3861(96)87620-8

[42] Tadmor Z., Gogos C. G.: Principles of polymer processing. Wiley, New Jersey (2006). 